\title{
Spatially resolved micro-X-ray fluorescence and micro-X-ray absorption fine structure study of a fractured granite bore core following a radiotracer experiment ${ }^{\hbar}$
}

\author{
Melissa A. Denecke ${ }^{\mathrm{a}, *}$, Boris Brendebach ${ }^{\mathrm{a}}$, Wout De Nolf ${ }^{\mathrm{b}}$, Gerald Falkenberg ${ }^{\mathrm{c}}$, Koen Janssens ${ }^{\mathrm{b}}$, Rolf Simon ${ }^{\mathrm{d}}$ \\ a Forschungszentrum Karlsruhe, Institut für Nukleare Entsorgung, P.O. Box 3640, D-76021 Karlsruhe, Germany \\ ${ }^{\mathrm{b}}$ Department of Chemistry, University of Antwerp, Universiteitsplein 1, B-2610 Antwerp, Belgium \\ ${ }^{c}$ Hamburger Synchrotronstrahlungslabor (HASYLAB) at DESY, Notkestr. 85, D-22603 Hamburg, Germany \\ d Forschungszentrum Karlsruhe, Institut für Synchrotronstrahlung, P.O. Box 3640, D-76021 Karlsruhe, Germany
}

\section{A R T I C L E I N F O}

\section{Article history:}

Received 14 November 2007

Accepted 19 May 2009

Available online 6 June 2009

\section{Keywords:}

Microfocus

$\mu-X R D$

$\mu-X R F$

Actinide speciation

Neptunium

Column tracer studies

\begin{abstract}
A B S T R A C T
Spatially resolved X-ray absorption and fluorescence investigation with a micrometer-scale resolution on actinide-containing samples provide information necessary for safety assessment of nuclear waste disposal. In this paper one example of such an experiment is presented. This example entails neptunium speciation in a fractured granite bore core from the Swedish Äspö Hard Rock Laboratory following a radiotracer experiment using $\mu$-XAFS and $\mu$-XRF. In order to probe micro-volumes below the surface in the granite samples and thereby avoid potential changes in the Np speciation during cutting of the bore core, a confocal irradiation-detection geometry is employed. $\mu$-XAFS results for a selected granite bore core cross section with $\sim 3 \mathrm{nmol} \mathrm{Np/g}$ reveal that $\mathrm{Np}$, originally introduced as $\mathrm{Np}(\mathrm{V})$ in the tracer cocktail, is present in the granite in its reduced $\mathrm{Np}$ (IV) form. The $\mathrm{Np}(\mathrm{IV})$ is often present as particles, tens of $\mu \mathrm{m}$ in size. Elemental distribution maps show the tracer $\mathrm{Np}$ to be located in fissures and permeable channels not larger than $100 \mu \mathrm{m}$. The Np distribution appears often correlated with $\mathrm{Zn}$ also present in some fissures. We observe small granite fissures containing Fe (presumably $\mathrm{Fe}(\mathrm{II})$ ), where we do not detect any Np. It is feasible that inflowing $\mathrm{Np}(\mathrm{V})$ has a shorter residence time in large fractures, while in the smaller fissures migration is slower, leading to longer residence times, i.e., reaction times, where it is reduced to less soluble $\mathrm{Np}$ (IV) and becomes thereby immobilized.
\end{abstract}

(c) 2009 Elsevier B.V. All rights reserved.

\section{Introduction}

We perform spatially resolved X-ray fluorescence and absorption investigations using a focused synchrotron beam with micrometer dimensions ( $\mu$-XRF and $\mu$-XAFS) on granite bore core following a radiotracer experiment. Elemental distributions are obtained from $\mu$ XRF measurements, correlations between elements are characterized by comparison of the elemental distribution maps, and the $\mathrm{Np}$ oxidation state in "hot spot" volumes in the sample, whose location is identified in the Np distribution maps, determined from $\mu$-XAFS spectroscopy (both $\mu$-XANES and $\mu$-EXAFS). A confocal irradiationdetection geometry is employed, which, in addition to providing added depth information, allows us to minimize spectral interference from other elements by limiting the sample volume probed, as well as

\footnotetext{
is This paper was presented at the 19th "International Congress on X-ray Optics and Microanalysis" (ICXOM-19) held in Kyoto (Japan), 16-21 September 2007, and is published in the Special Issue of Spectrochimica Acta Part B, dedicated to that conference.

* Corresponding author. Tel.: +49 7247 825536; fax: +49 7247823927.

E-mail addresses: melissa.denecke@ine.fzk.de (M.A. Denecke), boris.brendebach@ine.fzk.de (B. Brendebach), wout.denolf@ua.ac.be (W. De Nolf), falkenbe@mail.desy.de (G. Falkenberg), koen.janssens@ua.ac.be (K. Janssens), rolf.simon@iss.fzk.de (R. Simon).
}

to record spectra below the sample surface, thereby avoiding surface oxidation artifacts possibly caused by cutting and polishing the granite slice.

The granite stems from an underground laboratory (the Swedish Äspö Hard Rock Laboratory), where the migration of radionuclides under near-real in situ conditions can be investigated [1]. These investigations are relevant for safety of nuclear waste disposal. The overall aim of such investigations is to assess mechanisms leading to actinide immobilization in high level nuclear waste repository host rock formations. The goal of this specific study is to determine if $\mathrm{Np}$ introduced onto a granite column in a radiotracer study and immobilized in the granite is associated with any identifiable elements from the measured elemental distribution maps. In addition, we wish to determine the valence state of the immobilized $\mathrm{Np}$ from $\mathrm{Np}$ L3 $\mu$-XAFS recorded at $\mathrm{Np}$ hot spots. This experiment is also designed to explore the applicability of the technique to a sample containing only a trace concentration level, in this case approximately $3 \mathrm{nmol} \mathrm{Np/g}$ granite.

\section{Experimental section}

A polished slice of a fractured granite bore core column $(150 \mathrm{~mm}$ original column length, $52 \mathrm{~mm}$ in diameter) from the Swedish Äspö 

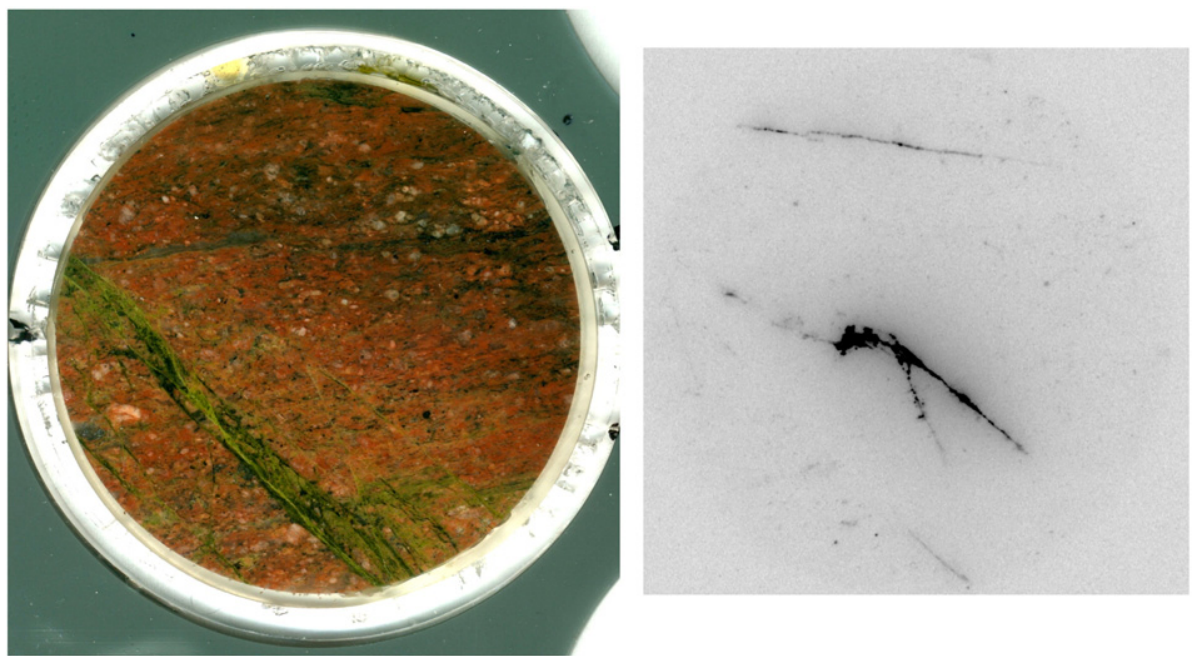

Fig. 1. Photograph of the granite bore core cross section studied and its autoradiographic image showing the distribution of radioactivity.

Hard Rock Laboratory used in a radiotracer experiment is studied in our $\mu$-focus X-ray experiments. Details of the tracer experiment can be found in [2]. In this experiment, the bore core was subjected to $14 \mathrm{~mL}$ radioisotope containing tracer cocktail in Äspö groundwater. The cocktail included $10^{-5} \mathrm{~mol} / \mathrm{dm}^{3}{ }^{237} \mathrm{~Np}$, added as $\mathrm{Np}(\mathrm{V})$. Elution was under pressure with $80 \mathrm{~mL}$ Äspö groundwater, whereby $26 \%$ of the $\mathrm{Np}$ introduced onto the column was finally recovered. At the end of the experiment, the column was cut perpendicular to the column axis into $4 \mathrm{~mm}$ thick sections. ICP-MS analysis of abraded material from cutting sections and g-counting ( $312 \mathrm{keV}$ line of ${ }^{233} \mathrm{~Pa}$ daughter) of sections showed the highest $\mathrm{Np}$ concentration $(\sim 3 \mathrm{nmol} \mathrm{Np} / \mathrm{g}$ granite material or $<1 \mathrm{ppm}$ ) remaining on the column to be located in the section originating $30 \mathrm{~mm}$ from the column top. A photograph of the section and an autoradiographic image showing the distribution of radioactivity in the granite core section are displayed in Fig. 1. Comparison of the autoradiographic and optical images of the sample shows the radioactivity to be localized in small granite fractures.
The $\mu$-XRF measurements using a band pass of wavelengths are made at the Fluo-Topo Beamline (ANKA, Karlsruhe) and at beamline $\mathrm{L}$ (HASYLAB, Hamburg). Either a $\mathrm{Si}$ drift or a $\mathrm{Si}(\mathrm{Li})$ solid state fluorescence detector is used in all $\mu$-XRF and $\mu$-XAFS experiments. Fluorescence intensities of elements in the sample for generating distribution maps are isolated from the full fluorescence signal via least-square fits using the AXIL software package from the University of Antwerp [3]. In order to assure that the Np L $\alpha 1$ signal (13.94 keV) is sufficiently well-resolved from the energetically similar $\mathrm{Sr} \mathrm{K} \alpha 1$ line (14.17 keV), an excitation energy lying above the Np L2 absorption edge ( $21.6 \mathrm{keV}$ ) of $\sim 23 \mathrm{keV}$ is used to also observe the Np L $\beta 1$ line. The elemental distributions obtained using the $L \alpha 1$ and $L \beta 1$ intensities are comparable, showing that spectral interference in the setup is not a problem.

Two half-lenses are used in the confocal setup; one is used to focus the incident primary beam and the other used as collimating half-lens in front of the detector [4]. Upon scanning sample areas at selected

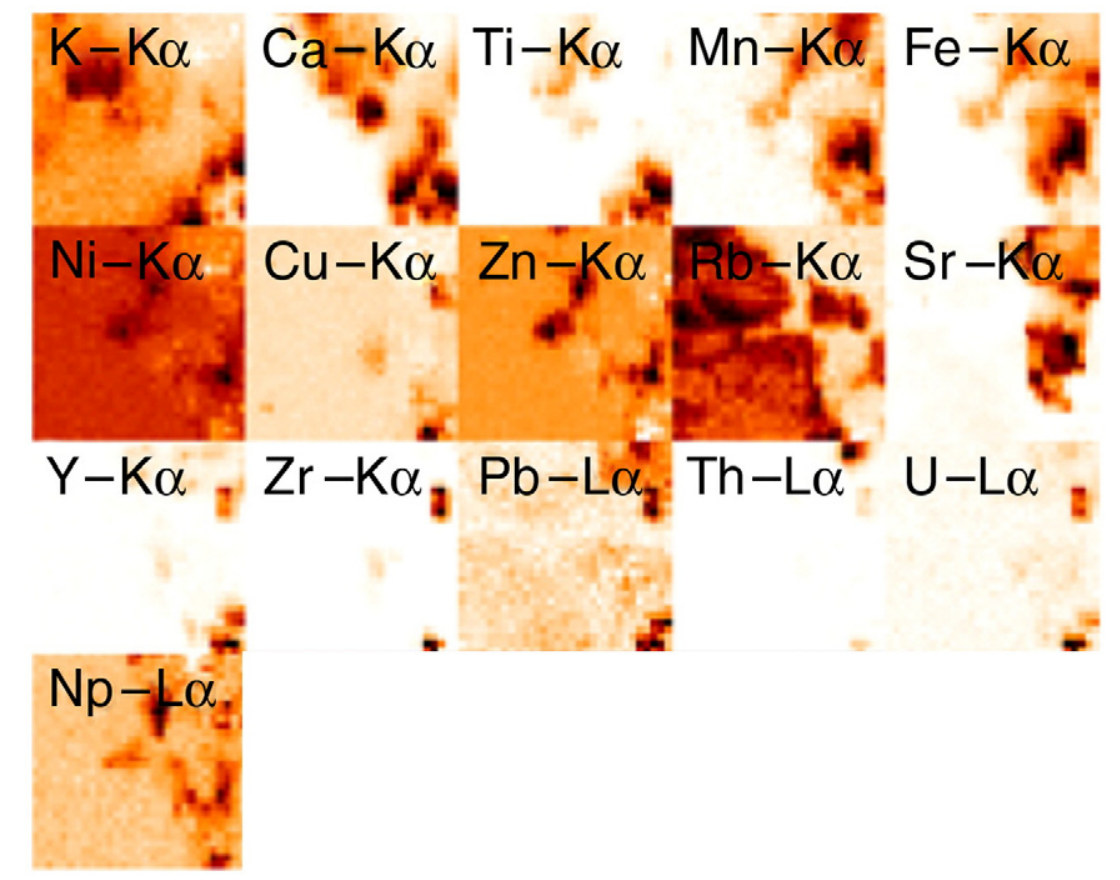

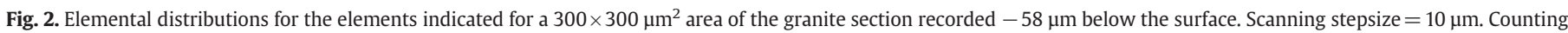
time $=5 \mathrm{~s}$. 
depths, tomographic cross sections visualizing the distribution of elements may be easily recorded. By varying the energy of the beam across the Np L3 absorption edge at a constant sample position, X-ray absorption fine structure (XAFS) spectra are recorded. The primary focusing optic is a planar compound refractive lens (CRL) at ANKA and a polycapillary (PC) at HASYLAB. A second PC between sample and detector is used as collimating optic at both stations. The CRL is fabricated at the Forschungszentrum Karlsruhe Institut für Mikrostrukturtechnik [5] and delivers a focused X-ray spot of $2 \times 5 \mu \mathrm{m}^{2}$ $(\mathrm{V} \times \mathrm{H})$. The diameter of the focal spot delivered by the PC is measured to be $12 \mu \mathrm{m}$ and the depth resolution $23 \mu \mathrm{m}$.

Monochromatic X-rays from $\mathrm{Si}(111)$ crystals in the double-crystal monochromator are used for collecting $\mu$-XAFS at beamline L. The energy of the monochromatic beam for recording Np L3 edge is calibrated against the first derivative XANES spectrum of a $\mathrm{Zr}$ foil, defined as $17.998 \mathrm{keV}$ [6]. The Np L3 edge XANES and EXAFS are isolated from raw data using standard techniques and the Athena software [7].

\section{Results and discussion}

Fig. 2 shows the $\mu$-XRF elemental distributions for the main elements having fluorescence lines above $3 \mathrm{keV}$ observed in the sample, measured using the CRL confocal setup at ANKA, at a depth approximately $-58 \mu \mathrm{m}$ below the sample surface. This image is recorded at a $300 \mu \mathrm{m} \times 300 \mu \mathrm{m}$ area of the granite section, where the autoradiographic image indicates major alpha activity and the optical image reveals a number of holes, which appear to be pore cross sections in the granite. The granite fracture fill material has a high Fe content [2] and we consider the Fe distribution to indicate locations of granite fractures. We observe areas of higher Np content to be located near, but necessarily on top of the pixels with high amounts of Fe. Visual comparison of the distributions shows the $\mathrm{Zn}$ and the $\mathrm{Np}$ distributions to be qualitatively similar.

One observation in Fig. 2 is clear: we are successful in dealing with potential spectral interference by using an excitation energy above the Np L2 edge. Fig. 3 depicts the XRF spectrum registered for a single pixel at the Np hot spot with high Np L $\alpha 1$ intensity observed in the Np distribution in Fig. 2. Numerous K $\alpha 1$ and L $\alpha 1$ lines (Rb, Th, U, Sr) lie energetically near the Np L $\alpha 1$ (L3 $\rightarrow$ M5) line at $13.94 \mathrm{keV}$, whereas the Np LB1 line (L2 $\rightarrow$ M4) line at $17.75 \mathrm{keV}$ is well-resolved (indicated with an arrow). This aids in fits to the XRF spectra using the AXIL program to extract intensities for constructing the Np distribution maps, as the theoretical intensity ratio for the L $\alpha 1$ and $L \beta 1$ helps

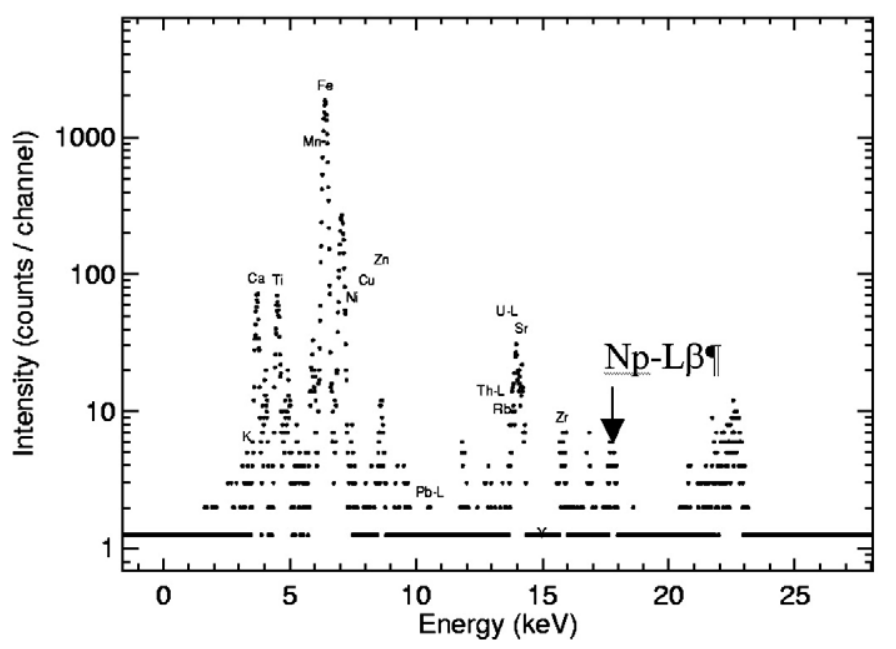

Fig. 3. The XRF spectrum registered for a pixel at the Np hot spot with high Np L $\alpha 1$ intensity observed in the Np distribution depicted in Fig. 2.
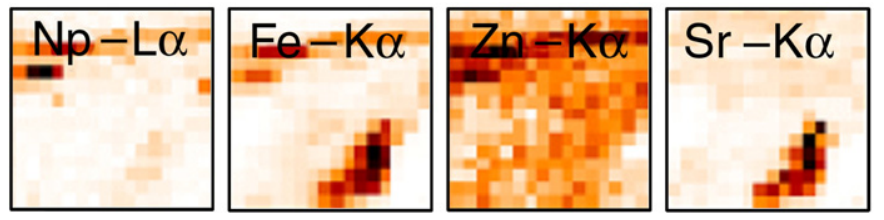

Fig. 4. $\mu$-XRF distribution maps recorded in confocal geometry for $\mathrm{Np}, \mathrm{Fe}, \mathrm{Zn}$, and $\mathrm{Sr}$ of a $300 \times 300 \mu \mathrm{m}^{2}$ section $\left(20 \times 20 \mu \mathrm{m}^{2}\right.$ step size; $7 \mathrm{~s}$ counting time $)$ of the granite core slice $\sim 40 \mu \mathrm{m}$ below the surface.

constrain the fit. In addition, the confocal geometry is helpful by probing restricted volumes of the sample.

The good resolution is also demonstrated in the distributions in the granite measured using the PC as primary focus at a depth approximately $-40 \mu \mathrm{m}$ below the surface (Fig. 4). That the measured $\mathrm{Np}$ and $\mathrm{Sr}$ distributions differ from one another is further indication that spectral interference is not a problem. We also observe in Fig. 4 that the Fe distribution follows a branched fissure in the granite with dimensions of $100 \mu \mathrm{m}$ or less. The $\mathrm{Np}$ is located near the smaller branch in the upper part of the image, but is absent from the larger fissure portion at the lower part of the image. This particular $\mu$-XRF map also displays our general qualitative observation that $\mathrm{Np}$ is often found associated with $\mathrm{Zn}$. In addition, we find that the Np appears concentrated in small hot spots with tens of $\mu \mathrm{m}$ dimensions, which may indicate their being in a particulate form.

In order to determine the valence state of the immobilized $\mathrm{Np}$ in the granite, Np L3 $\mu$-XANES and $\mu$-EXAFS are recorded at pixels with high Np L $\alpha 1$ intensity. Note that these spectra are recorded for a specimen with a nominal $\mathrm{Np}$ concentration of $3 \mathrm{nmol} / \mathrm{g}$ or $<1 \mathrm{ppm}$. The clear advantage of using a microfocus beam for X-ray spectroscopy on dilute, heterogeneous samples is obvious in this example. Comparison of the Np L3 XANES of $\mathrm{Np}$ in the granite with $\mathrm{Np}$ (IV) and $\mathrm{Np}(\mathrm{V})$ references (Fig. 5) reveals a similarity between the $\mathrm{Np}$ in granite and the $\mathrm{Np}$ (IV) XANES, indicating that the $\mathrm{Np}$ hot spot contains $\mathrm{Np}$ (IV). The symmetric form and high intensity of the main absorption feature, called the white line $(\mathrm{WL})$, the energy position of this WL (17.621 keV for all sample volumes probed), and the lack of a multiple scattering feature at 10 to $15 \mathrm{eV}$ above the $\mathrm{WL}$, characteristic of the neptunyl $(\mathrm{Np}(\mathrm{V}))$ ion [8], are strong indicators that $\mathrm{Np}$ is in the tetravalent state in the granite.

We also register the Np L3 EXAFS spectrum, as systematic XANES/ EXAFS investigations have shown that analysis of L3 edge EXAFS spectra is more sensitive than XANES for detecting $N p(V)$ alongside $\mathrm{Np}$ (IV) cations in samples containing predominantly $\mathrm{Np}$ in the tetravalent oxidation state [8]. The EXAFS spectrum (Fig. 6) is noisy but the quality is sufficient to extract a meaningful Fourier transform

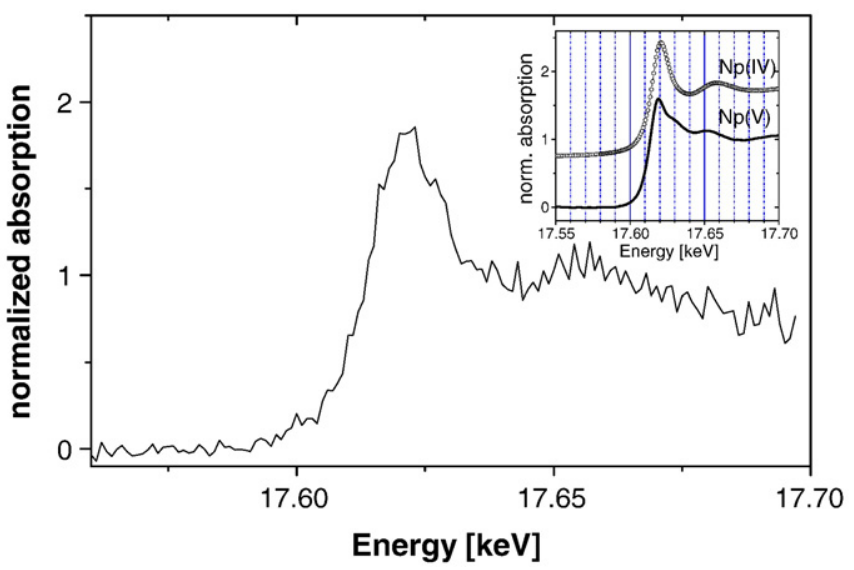

Fig. 5. Np L3 $\mu$-XANES measured at the Np hot spot in Fig. 4 around $-50 \mu \mathrm{m}$ below the sample surface. Inset: $\mathrm{Np}(\mathrm{IV})$ and $\mathrm{Np}(\mathrm{V})$ reference spectra. 

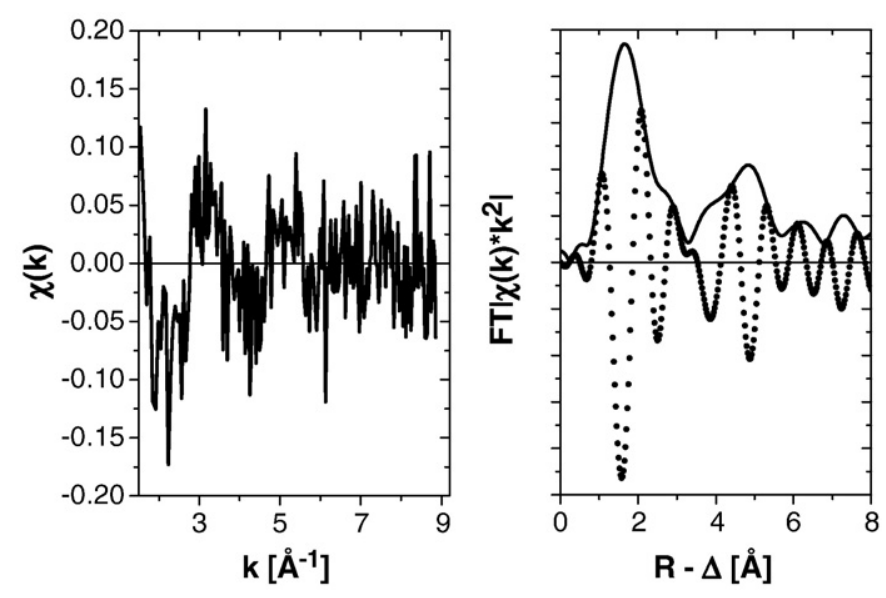

Fig. 6. Np L3 edge EXAFS $\left(\chi(k)\right.$; left) and its corresponding $k^{2}$-weighted Fourier transform (FT) data (right).

(FT) spectrum. In the FT we observe no splitting of the first oxygen shell into two peaks expected for $\mathrm{Np}(\mathrm{V})$, representing the short NpOax approximately $1.83 \AA$ distance in $\mathrm{Np}(\mathrm{V})$ species (expected at R- $\Delta$ $\sim 1.55 \AA$ uncorrected for phase shifts) and an associated longer distance for atoms in the neptunyl equatorial plane coordination polyhedron [8]. The measured FT in the granite shows a single major first shell FT characteristic for $\mathrm{Np}(\mathrm{IV})$. Similar results are reported for $\mathrm{U}(\mathrm{IV})$ in a U-rich sediment [9].

In order to corroborate the qualitative observation that $\mathrm{Np}$ is associated with $\mathrm{Zn}$, we plot the $\mathrm{Zn} \mathrm{K} \alpha 1$ versus the $\mathrm{Np} L \alpha 1$ intensities, as well as the Fe $K \alpha 1$ versus the $\mathrm{Np} L \alpha 1$ intensities, of individual pixels from the distribution images. The result is shown in Fig. 7. The lines in the figure are a guide to the eye with slopes $1 / 2$ and 2; most data points lie within the fan defined by these two slopes. This indicates a direct correlation between $\mathrm{Np}$ and $\mathrm{Zn}$, as expected from our qualitative observations. In contrast, the $\mathrm{Fe} / \mathrm{Np}$ correlation plots are more complicated. We observe a clustering of data points along the $\mathrm{Fe}$ $\mathrm{K} \alpha 1$ intensity baseline in these plots, indicative of there being no correlation between $\mathrm{Fe}$ and $\mathrm{Np}$ in the pixels associated with these data points. However, we also observe a few data points along a straight line in the plot at bottom right of Fig. 7 and a general linear trend in the Fe/Np correlation at bottom left. Obviously there are areas in the sample, where Np is associated with Fe.

\section{Conclusions}

Analysis of the $\mu$-XAFS results allows us to conclude that Np, originally introduced as $\mathrm{Np}(\mathrm{V})$ into the column, is reduced to $\mathrm{Np}(\mathrm{IV})$ in the fractured granite following the radiotracer experiment. We note that without the spatial resolution of the experimental setup and the confocal geometry it would not have been possible to obtain this information on a dilute element (tracer concentration) in such a heterogeneous sample.

The distribution of $\mathrm{Np}(\mathrm{IV})$ is apparently associated with $\mathrm{Zn}$. We assume that, under the anaerobic conditions prevalent at the depth this granite was obtained, this is likely $\mathrm{ZnS}$. The observed correlation between $\mathrm{Zn}$ and $\mathrm{Np}$ may indicate that $\mathrm{ZnS}$ played a role in $\mathrm{Np}(\mathrm{V})$ reduction to $\mathrm{Np}(\mathrm{IV})$ and subsequent immobilization of this less soluble Np valence form. There are areas where a correlation between $\mathrm{Np}$ and $\mathrm{Fe}$ is observed, but other areas with none. The correlation between $\mathrm{Np}$ and Fe may indicate one or both of two things: $\mathrm{Np}(\mathrm{V})$ was immobilized by reduction to $\mathrm{Np}$ (IV) by $\mathrm{Fe}(\mathrm{II})$ and/or the $\mathrm{Np}$ is located in fissures, as $\mathrm{Fe}$ is an indicator element for granite fracture material. The sample regions, where no correlation between Fe and Np is found,
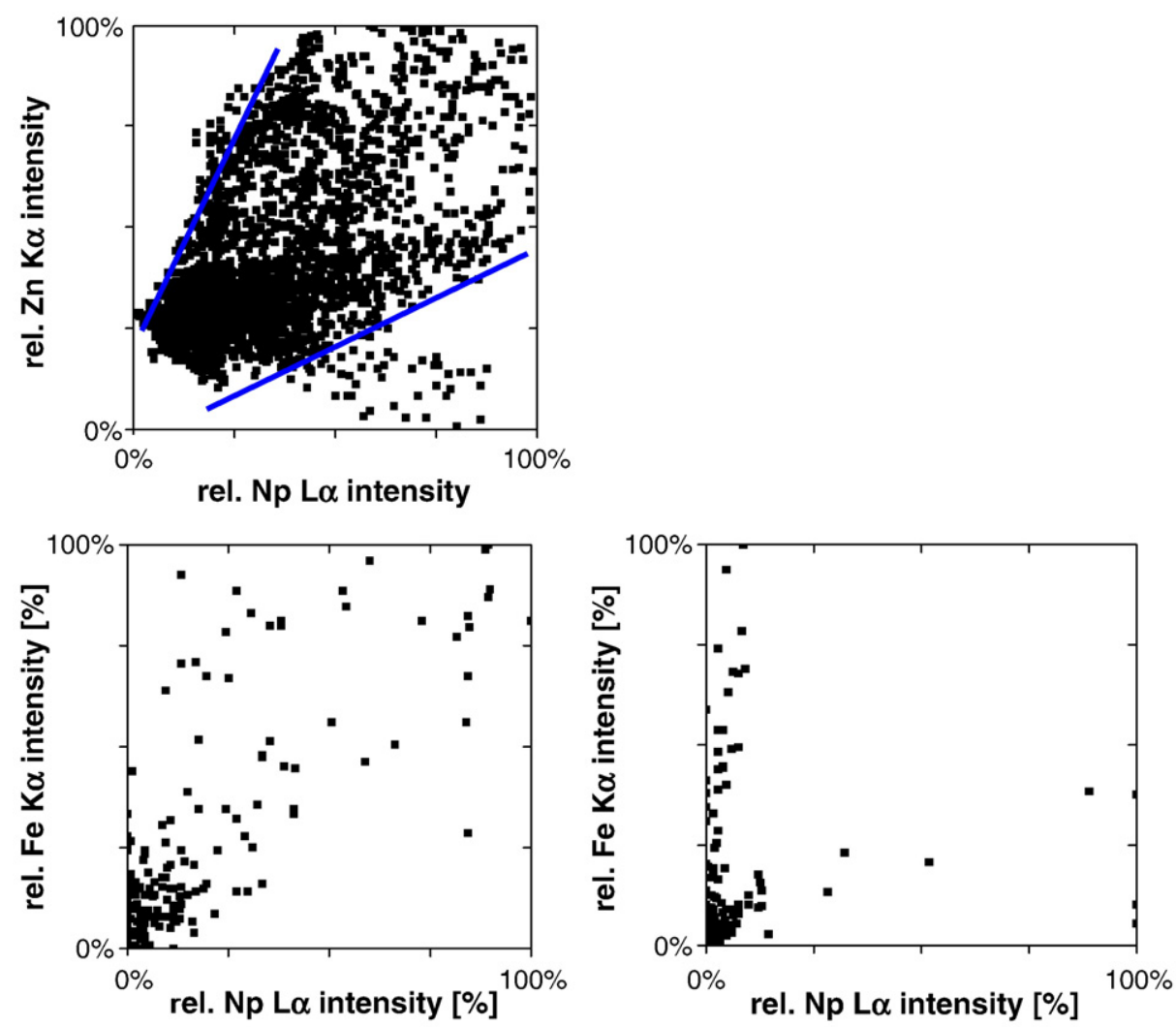

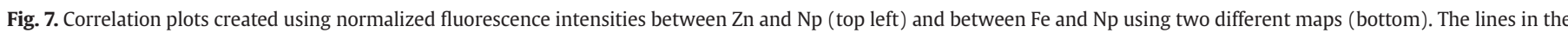
top figure are a guide to the eye with slopes $1 / 2$ and 2 . 
may be associated with fissures not easily accessible by inflowing groundwater carrying the Np tracer.

The measured Np distributions reveal $\mathrm{Np}$ to form particulates of having dimensions on the order of tens of $\mu \mathrm{m}$, which are themselves located in fissures and permeable channels in the granite not larger than $100 \mu \mathrm{m}$. It is feasible that during the tracer experiment inflowing $\mathrm{Np}$ has a shorter residence time in the large fractures, while in the smaller fissures migration is slower, leading to longer residence times, i.e., reaction times, resulting in $\mathrm{Np}(\mathrm{V})$ reduction and immobilization of less soluble $\mathrm{Np}(\mathrm{IV})$.

This study has implications for modeling scenarios of actinide release in a nuclear waste repository placed in a granite host rock formation. The redox conditions of the groundwater/granite obviously play a role, but so do the size and interconnectivity of the fractures and fissures in the granite.

\section{Acknowledgments}

We thank ANKA and HASYLAB for awarding us beamtime, E. Sobolla for preparation of the thin sections, and J. Römer for the autoradiographic measurements.

\section{References}

[1] M.A. Denecke, K. Janssens, B. Brendebach, W. De Nolf, G. Falkenberg J. Rothe, R. Simon, A. Somogyi, B. Vekemans, U. Noseck, in: B. Hedman, P. Pianetta (Eds.), Confocal $\mu$-XRF, $\mu$-XAFS, and $\mu$-XRD Studies of Sediment from a Nuclear Waste Disposal Natural Analogue Site and Fractured Granite Following a Radiotracer Migration Experiment, X-ray Absorption Fine Structure - XAFS13, American Institute of Physics, Melville, NY, 2007, pp. 187-189.

[2] J. Römer, B. Kienzler, P. Vejmelka, E. Soballa, A. Görtzen, M. Fuß, FZK-Wissenschaftliche Berichte FZKA6770, October 2002.

[3] B. Vekemans, K. Janssens, L. Vincze, F. Adams, P. Van Espen, Analysis of X-ray spectra by iterative least squares (AXIL): new developments, X-ray Spectrom. 23 (1994) 278-285.

[4] K. Janssens, K. Proost, G. Falkenberg, Confocal microscopic X-ray fluorescence at the HASYLAB microfocus beamline: characteristics and possibilities, Spectrochim. Acta Part B 59 (2004) 1637-1645.

[5] V. Nazmov, E. Reznikova, A. Somogyi, J. Mohr, V. Saile, Planar sets of cross X-ray refractive lenses from SU-8 polymer, Proceedings of SPIE, vol. 5539, 2004, pp. 235-242.

[6] W.H. McMaster, N. Kerr Del Grande, J.H. Mallett, J.H. Hubbell, Lawrence Livermore National Laboratory Report, UCRL-50174 Section II Revision I, 1969.

[7] http://cars9.uchicago.edu/ ravel/software/aboutathena.html.

[8] M.A. Denecke, K. Dardenne, C.M. Marquardt, $\mathrm{Np}(\mathrm{IV}) / \mathrm{Np}(\mathrm{V})$ valence determinations from Np L3 edge XANES/EXAFS, Talanta 65 (2005) 1008-1014.

[9] M.A. Denecke, K. Janssens, K. Proost, J. Rothe, U. Noseck, Confocal micro-XRF and micro-XAFS studies of uranium speciation in a tertiary sediment from a waste disposal natural analogue site, Environ. Sci. Technol. 39 (2005) 2049-2058. 